\title{
USO DE NOVAS TECNOLOGIAS PARA A INCLUSÃO DE DEFICIENTES AUDITIVOS NO ENSINO DE QUÍMICA
}

\section{USE OF NEW TECHNOLOGIES FOR THE INCLUSION OF HEARING DEFICIENTS IN CHEMISTRY TEACHING}

Wellington Virgolino Lima da Silva ${ }^{1}$; Alvaro Gustavo Nascimento Silva ${ }^{2}$; Jameson Monteiro Lins ${ }^{3}$; Romildo de França Carneiro Júnior ${ }^{4}$; Hércules Santiago Silva ${ }^{5}$.

\section{INTRODUÇÃO}

Este trabalho tem como principal objetivo a intenção e a integração de estudantes com deficiência auditiva através do uso de novas ferramentas tecnológicas no processo de ensinoaprendizagem de química no ensino básico. Para tanto foi produzida e transmitida uma videoaula com intérprete da língua brasileira de sinais (LIBRAS) e legendas na língua portuguesa, numa abordagem temática, relacionado a química ao cotidiano dos estudantes com intuito de facilitar a compreensão do conteúdo abordado no vídeo.

\section{RELATO DE EXPERIÊNCIA}

A experiência foi realizada através da transmissão de uma videoaula sobre uma dramatização que trata de uma problemática envolvendo a química no dia a dia, o vídeo foi tratado na forma de um diálogo sobre a importância do uso de soda cáustica $(\mathrm{NaOH})$ para desentupir pias, algo muito comum nas residências brasileiras. Projetamos um conteúdo explicativo e através do intérprete de LIBRAS podemos socializar a informação aos estudantes na primeira parte do vídeo. Já na segunda parte do vídeo, o conteúdo de química foi mediado de uma maneira diferente, através da legendas em português.

Na pesquisa de campo, pedimos autorização ao gestor da Escola Luíza Guerra, no município do Cabo de Santo Agostinho -PE, para apresentar o vídeo para estudantes surdos do ensino médio. No momento da apresentação tivemos ajuda de três professoras intérpretes, que reuniram os estudantes em uma única sala de aula, e assim puderam debater, mediar e perguntar através de sinais, as dúvidas referente ao vídeo.

Após o vídeo ser transmitido para os estudantes, foi distribuído um questionário referente os dados pessoais e tópicos sobre a forma de comunicação, opinião sobre o vídeo e a sua correlação com a química. Os resultados foram dispostos em gráficos e suas informações

\footnotetext{
1 Licenciatura em Química, Instituto Federal de Pernambuco, wellingtonvirgolino16@gmail.com

2 Licenciatura em Química, Instituto Federal de Pernambuco, quimica1997@ hotmail.com

${ }^{3}$ Licenciatura em Química, Instituto Federal de Pernambuco, jamesonmonteiro@ hotmail.com

${ }^{4}$ Licenciatura em Química, Instituto Federal de Pernambuco, romildo.junior.2011@ hotmail.com

${ }^{5}$ Mestre em Química, Universidade Federal de Pernambuco, herculessantiago@ipojuca.ifpe.edu.br
} 
devidamente estratificadas e analisadas como veremos a seguir:

Gráfico 1: Dados pessoais dos surdos.

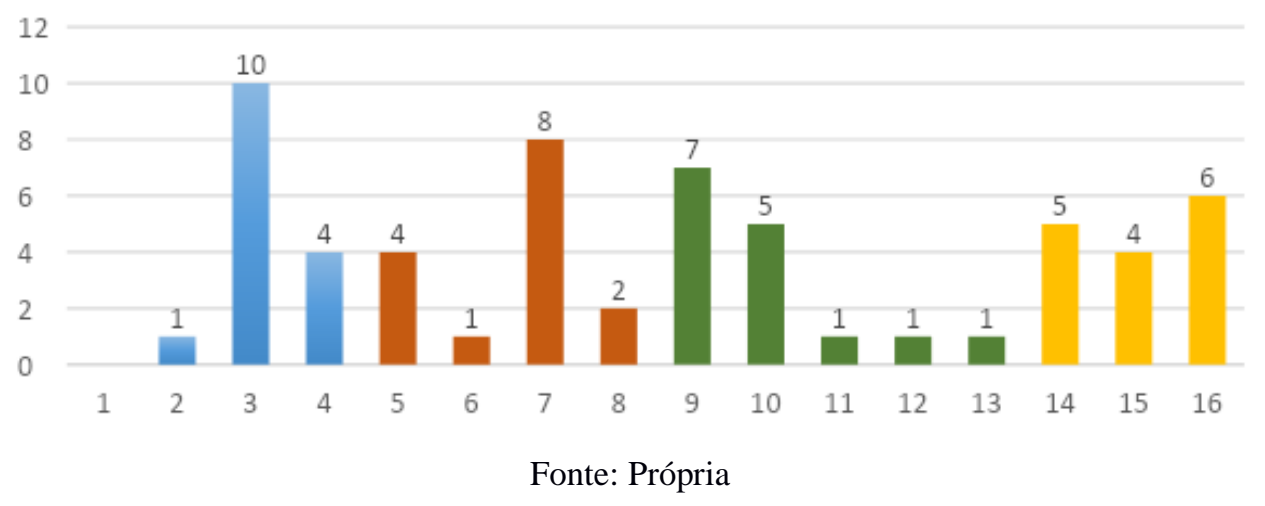

Como podemos observar no Gráfico1, dentre os quinze estudantes surdos do ensino médio, vemos que cinco cursam o $1^{\circ}$ ano do ensino médio, que corresponde a 33,3\% do total de alunos, quatro cursam o $2^{\circ}$ ano e seis cursam o $3^{\circ}$ ano do ensino médio que corresponde a respectivamente, $26,6 \%$ e $40 \%$ do total de estudantes. Foi observado que desses alunos cerca de 66,6\% tem entre 18 anos e 22 anos, ou seja, apresentam uma grande distorção de série/idade, devido à grande dificuldade na compreensão dos conteúdos ministrados, da comunicação entre interprete-docente-discente que dificulta a socialização do conhecimento no processo de ensino-aprendizagem. Vale salientar os estudantes surdos são inseridos em classes mistas, ou seja, com estudantes surdos e ouvintes, afim maximizar a integração dos estudantes surdos, para ter uma melhor socialização e aprimorar o conhecimento dos conteúdos do ensino médio. (Rosana Prado, 2015).

Gráfico 2: Formas de comunicação.

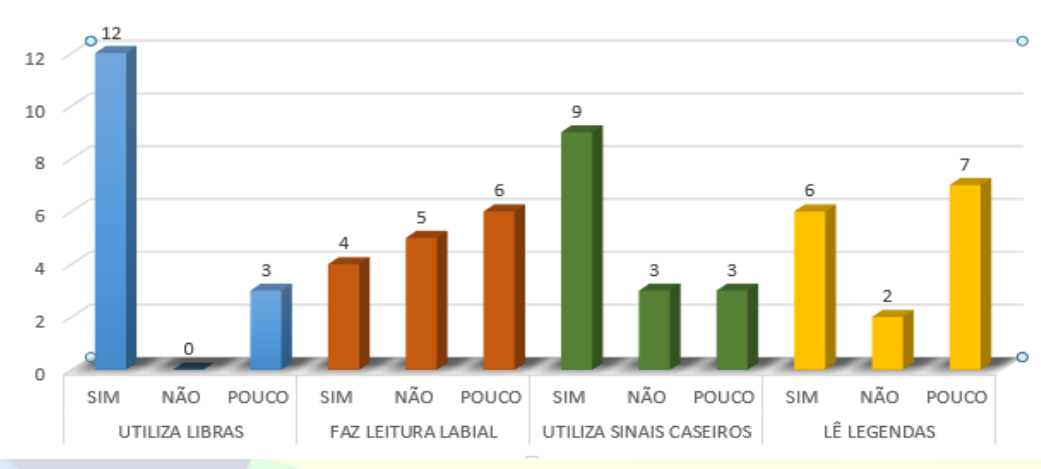

Fonte: Própria

No Gráfico 2, vemos que $80 \%$ dos estudantes surdos sabem LIBRAS, $60 \%$ usam sinal caseiro, 26,6\% usam leitura labial e $40 \%$ lê legendas. A partir desses dados, podemos analisar que a maioria dos estudantes surdos possuem linguagem interna (sinais caseiros) muito rica e possuem graus variados de informações do saber formal, mas com grande potencial para expandir esse conhecimento, que é fundamental para sua escolaridade (ROSANA P.; 
VALDELÚCIA A. C., 2017).

A Língua Brasileira de Sinais (LIBRAS) é a língua oficial dos surdos, com características, visual-espacial, que possui estrutura própria (Paula Nadal, 2010). No estudo de campo foi possível observar que muitos dos estudantes presentes naquele local, apresentavam problemas de alfabetização na língua portuguesa desde o ensino fundamental e chegam ao ensino médio se comunicando unicamente por LIBRAS, o que dificulta o processo de ensinoaprendizagem, pois nem todos envolvidos no processos sabem se comunicar em LIBRAS, principalmente os professores e a maior parte dos alunos ouvintes. Por isso é muito importante para uma criança surda ter um desenvolvimento na educação infantil junto com ouvintes e ser alfabetizada na língua portuguesa nessa faixa etária para ter um melhor processo de interação e integração onde o aprendizado acontece com mais facilidade (GÓES, 2002).

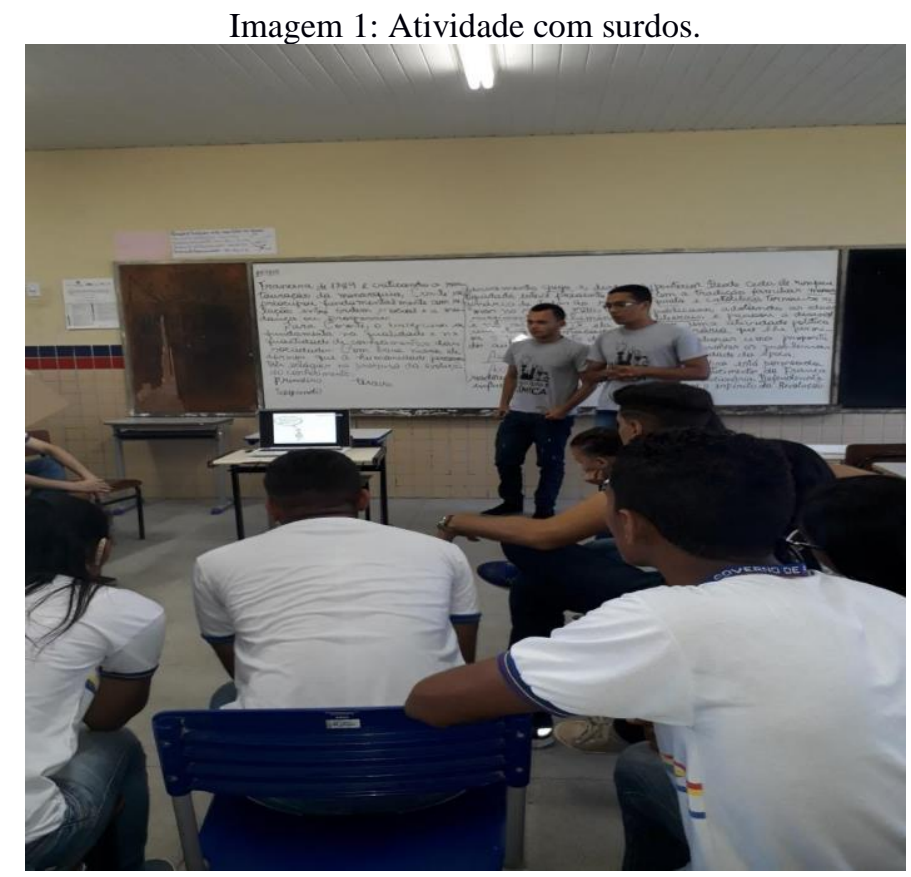

Fonte: Própria

\section{CONSIDERAÇÕES FINAIS}

$\mathrm{Na}$ abordagem foi realizada uma dramatização, sobre o desentupimento de pias com soda cáustica em uma videoaula, com intérprete e legendas para socializar o conteúdo aos estudantes surdos. Podemos analisar que os estudantes surdos, ficaram entusiasmados com o uso da ferramenta didática na sala de aula, que se mostrou bastante promissora, mas tiveram dificuldade com as legendas em português, pois muitos deles não eram bilíngues, ou seja, não tiveram um ensino qualificado da língua portuguesa. Numa perspectiva futura seria interessante que a produção de videoaula seja produzidas exclusivamente em LIBRAS a fim de minimizar os problemas causados pela falta de alfabetização na língua portuguesa. 


\section{REFERÊNCIAS}

GÓES, M. C. R. de. LINGUAGEM SURDEZ E EDUCAÇÃO: Campinas: Autores associados, 2002.

HOFFMAN, J. AVALIAÇÃO MEDIADORA: uma prática em construção da pré-escola à universidade. Porto Alegre: Mediação, 2001.

NADAL, PAULA. NOVA ESCOLA. O desafio de ensinar a língua: Mediação, 2010. Disponível em: <https://novaescola.org.br/conteudo/1533/o-desafio-de-ensinar-linguaportuguesa-a-alunos-surdos> Acesso em: 02 outubro 2018.

PRADO, ROSANA. INCLUSÃO DE ALUNOS SURDOS: uma proposta de educação bilíngue em escola pública. Niterói/RJ: Mediação, 2014.

PRADO, ROSANA; COSTA V. A. POLÍTICAS DE INCLUSÃO ESCOLAR E PRÁTICAS PEDAGÓgICAS NA EDUCAÇÃOBILÍNGUE DE ALUNOS SURDOS: Desafios do Atendimento Educacional Especializado. Fluminense/RJ: Mediação, 2017. 


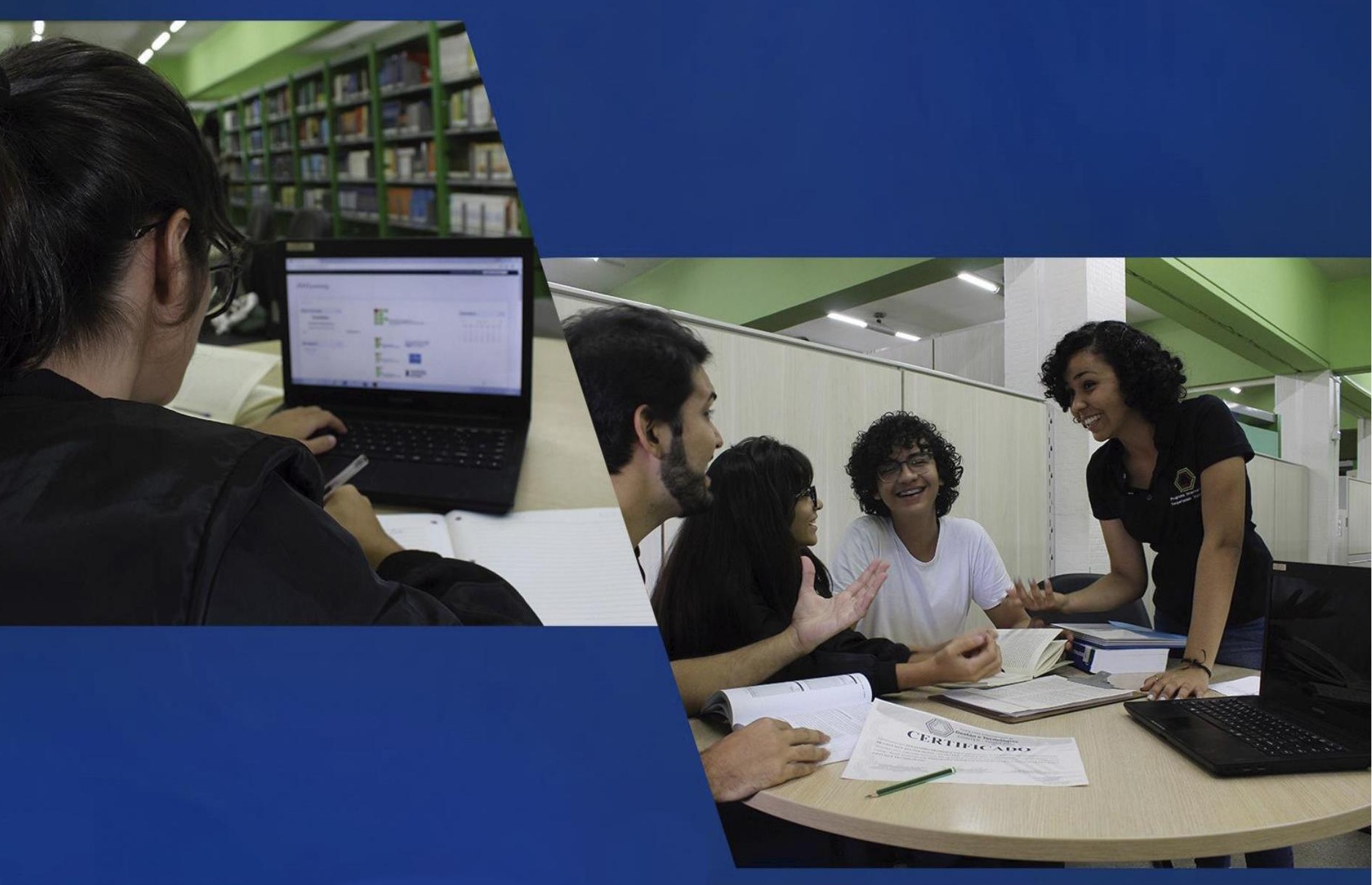

